Article

\title{
Improvement in Carbonization Efficiency of Cellulosic Fibres Using Silylated Acetylene and Alkoxysilanes
}

\author{
Maria Mironova *, Igor Makarov ${ }^{D}$, Lyudmila Golova, Markel Vinogradov, Georgy Shandryuk \\ and Ivan Levin \\ A.V. Topchiev Institute of Petrochemical Synthesis, Russian Academy of Sciences, 119991 Moscow, Russia; \\ makarov@ips.ac.ru (I.M.); glk@ips.ac.ru (L.G.); vin1989@ips.ac.ru (M.V.); gosha@ips.ac.ru (G.S.); \\ levin@ips.ac.ru (I.L.) \\ * Correspondence: mariamir@inbox.ru; Tel.: +7-495-647-5927
}

Received: 6 September 2019; Accepted: 25 September 2019; Published: 28 September 2019

\begin{abstract}
Comparative studies of the structure and thermal behavior of cellulose and composite precursors with additives of silyl-substituted acetylene and alkoxysilanes were carried out. It is shown that the introduction of silicon-containing additives into the cellulose matrix influenced the thermal behavior of the composite fibers and the carbon yield after carbonization. Comparison of the activation energies of the thermal decomposition reaction renders it possible to determine the type of additive and its concentration, which reduces the energy necessary for pyrolysis. It is shown that the $\mathrm{C} / \mathrm{O}$ ratio in the additive and the presence of the $\mathrm{Si}-\mathrm{C}$ bond affected the activation energy and the temperature of the beginning and the end of the pyrolysis reaction.
\end{abstract}

Keywords: Cellulose fiber; Lyocell; N-methylmorpholine-N-oxide; silicon-containing additives; thermal properties

\section{Introduction}

By means of the solid phase dissolution of cellulose in $\mathrm{N}$-methylmorpholine- $\mathrm{N}$-oxide (NMMO), a direct solvent for cellulose, it is possible to obtain highly concentrated solutions and to spin the Lyocell-type fibers [1]. Recently, these fibers have attracted a lot of attention, not only as an alternative to rayon textile material, but also as precursors of carbon fibers [2].

The main problems of thermal transformation of cellulose fibers into carbon fibers are the increase of the carbon yield and formation of the necessary structures that provide good mechanical properties [3]. The theoretically possible value of the carbon yield in the carbonization process of cellulose is $44.4 \%$ [4]. In order to get as close as possible to this value, it is recommended to use active substances (the catalysts) that direct the process of pyrolysis towards the formation of carbon structures and prevent the byproducts (e.g., levoglucosanes) caused by the removal of carbon in gas form $[5,6]$.

Catalysts of pyrolysis and flame retardants can be applied by impregnation of the precursor fibers with solutions of active substances followed by their drying $[7,8]$. The most widely used pyrolysis catalysts for cellulose are ammonium chloride and ammonium sulfate. Recently, silicon-containing catalysts have been proposed as an alternative to these active agents. Their use allows carbon fibers with a mechanical strength of more than $1 \mathrm{Gpa}$ to be obtained. In [9-14], predominant data were given on the use of silicon-containing compounds for obtaining carbon fiber, in particular, in [10], the application of Tetraethoxysilane (TEOS) makes it possible to obtain carbon fibers with a diameter of $5.5 \mu \mathrm{m}$, a tensile strength of $930 \mathrm{Mpa}$, and an elastic modulus of $38 \mathrm{GPa}$, with a carbon yield of $\sim 14.5 \%$.

The introduction of the pyrolysis catalysts and flame retardants into the polymer matrix can be considered as an alternative method of their application, which achieves a better distribution 
of the active substance in the volume of the fiber and reduces the number of stages of processing (Figure 1) [15,16].

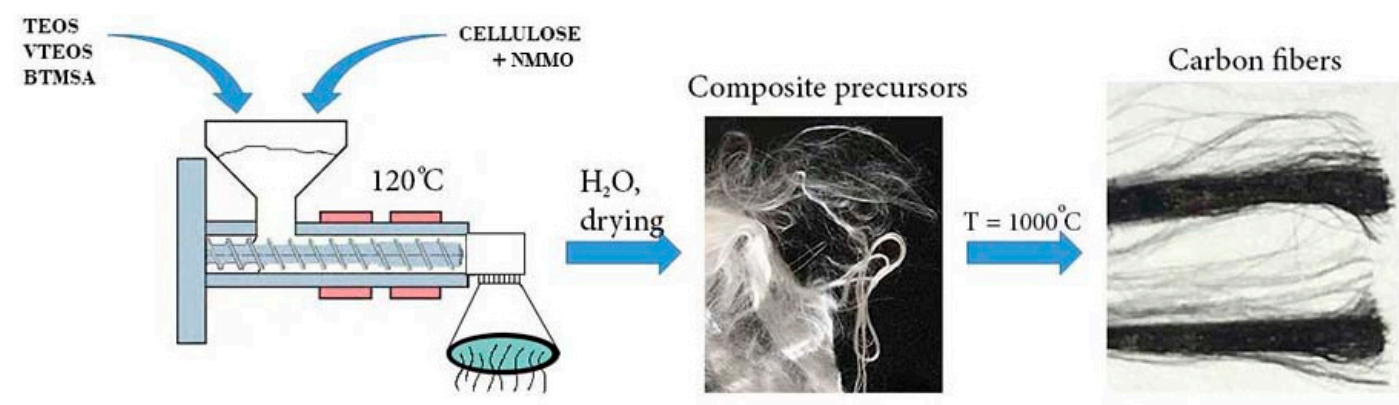

Figure 1. Basic stages of cellulose composite precursors and carbon fibers production. TEOS, Tetraethoxysilane; VTEOS, Vinyltriethoxysilane; BTMSA, Bistrimethylsilyl acetylene; NMMO, $\mathrm{N}$-methylmorpholine-N-oxide.

Silicon-containing compounds as additives allow not only an increase in the carbon yield during heat treatment of fibers, but also to obtain carbon-silicon carbide fibers [17], and it is exactly this class of fibers which is the most interesting for obtaining heat-resistant materials [18].

Thermogravimetry Analysis (TGA) and Differential Scanning Calorimetry (DSC) methods are widely used to study the properties of carbon fiber precursors and to represent the conditions for their production [19]. However, the results of experiments cannot always be interpreted definitely. To obtain more accurate information, it is recommended to process the results mathematically. Thus, to determine the differences in thermal behavior, process staging, thermostability of synthetic polymers, polysaccharides, cellulose fibers, and so on, it is reasonable to evaluate the kinetic parameters of the decomposition using the Broido method [20-23].

The Broido formula allows for estimation of the activation energy of the thermal decomposition of cellulose [24]

$$
\ln [\ln (1 / y)]=A-E_{a} /(R T),
$$

where $y=\left(M_{t}-M_{e}\right) / M_{0}-M_{e}, M_{0}$ is the mass of the initial sample, $M_{t}$ is the sample mass at temperature $\mathrm{T}$ in the TG experiment, $\mathrm{M}_{\mathrm{e}}$ is the final mass of the sample, $E_{a}$ is the activation energy, $T$ is the temperature, and $R$ is the universal gas constant.

The purpose of this study was to compare the structure and thermal behavior of cellulose and composite precursors containing silyl-substituted acetylene and alkoxysilanes additives, by the TGA and DSC methods.

In this research, we report that the addition of silyl-substituted acetylene and alkoxysilanes into the cellulose matrix led to a decrease in the activation energy. Valuable information was obtained from the TGA; it is shown that $5 \%$ of the additive is sufficient to significantly increase the carbon yield compared to cellulose during heat treatment of fibers to $1000{ }^{\circ} \mathrm{C}$.

\section{Materials and Methods}

Concentrated cellulose dopes were prepared according to the method described in [25] from cellulose of the Baikal Cellulose and Paper Mill (Russia) (degree of polymerization was 600, $\mathrm{H}_{2} \mathrm{O}$ content $\sim 8 \%$, and $\alpha$-cellulose content not less than $94 \%$ ). As a solvent, $\mathrm{N}$-methylmorpholine- $\mathrm{N}$-oxide with a $\mathrm{T}_{\mathrm{m}}=120-160{ }^{\circ} \mathrm{C}\left(\mathrm{H}_{2} \mathrm{O}<10 \%\right)$ (Demochem, China) was used. The silicon-containing additives are shown in Table 1 (Sigma-Aldrich, USA).

For inhibition of the of thermo-oxidative degradation, $0.5 \%$ of propylgallate (Sigma-Aldrich, USA) was introduced to solution. 
Table 1. The main characteristics of organosilicon additives.

\begin{tabular}{|c|c|c|c|c|c|}
\hline The Compound & Structural Formula & $\mathrm{T}_{\mathrm{m}},{ }^{\circ} \mathrm{C}$ & $\mathrm{T}_{\text {boil }}{ }^{\circ} \mathrm{C}$ & $\begin{array}{l}\text { Density, } \mathrm{g} / \mathrm{cm}^{3} \\
\left(\mathrm{~T}=25^{\circ} \mathrm{C}\right)\end{array}$ & $\begin{array}{l}\text { Viscosity, } \eta, \\
\text { mPa.s } \\
\left(\mathrm{T}=20^{\circ} \mathrm{C}\right)\end{array}$ \\
\hline $\begin{array}{c}\text { Tetraethoxysilane } \\
\text { (TEOS) (ID 24848042) }\end{array}$ & & -82.5 & 170 & 0.933 & 0.75 \\
\hline $\begin{array}{l}\text { Vinyltriethoxysilane } \\
\text { (VTEOS) (ID } \\
\text { 24850510) }\end{array}$ & $\overbrace{\mathrm{CH}_{3}}^{\mathrm{CH}_{2}}$ & $<0$ & 160 & 0.910 & 0.7 \\
\hline $\begin{array}{l}\text { Bistrimethylsilyl } \\
\text { acetylene (BTMSA) } \\
\text { (ID 24851275) }\end{array}$ & 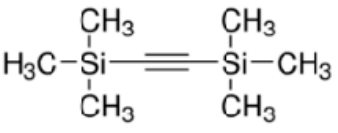 & 22 & 136 & 0.752 & - \\
\hline
\end{tabular}

As the main objects under consideration, the fibers obtained from the filled cellulose solutions in the NMMO with a weight ratio of 95/5 and 90/10 (cellulose/organosilicone additive) were studied (Table 2).

Table 2. Designation of the composite fibers.

\begin{tabular}{clcc}
\hline \multirow{2}{*}{ Sample } & \multicolumn{3}{c}{ Ratio of Components } \\
\cline { 2 - 4 } & $\mathbf{0}$ & $\mathbf{9 5 / 5}$ & $\mathbf{9 5 / 1 0}$ \\
\hline Cellulose/TEOS & $\mathrm{L}$ & $\mathrm{T}-5$ & $\mathrm{~T}-10$ \\
Cellulose/VTEOS & $\mathrm{L}$ & $\mathrm{VT}-5$ & $\mathrm{VT}-10$ \\
Cellulose/BTMSA & $\mathrm{L}$ & $\mathrm{B}-5$ & $\mathrm{~B}-10$ \\
\hline
\end{tabular}

The cellulose and composite precursors were spun on a capillary viscometer equipped with the fiber winding system Rheoscope 1000 (CEAST, Italy) $(\mathrm{d}=1 \mathrm{~mm}, 1 / \mathrm{d}=40)$ by a dry-jet wet method with a spinning speed of $\sim 100 \mathrm{~m} / \mathrm{min}$.

The thermal behavior of the fibers was examined on a TGA/DSC combined thermal analysis instrument, Mettler Toledo (Switzerland). The measurements were carried out in the temperature range of $30-1000{ }^{\circ} \mathrm{C}$ at a heating rate of $10^{\circ} \mathrm{C} / \mathrm{min}$. The flow rate of the argon was $10 \mathrm{~cm}^{3} / \mathrm{min}$. Alumina crucibles of $70 \mu \mathrm{L}$ were used.

The morphology of the fiber's surfaces and cross-sections was studied by the scanning electron microscope JSM U-3 (JEOL, Japan).

The structure of the fibers was studied by the X-ray diffraction method on a 12-kW generator Rigaku (Japan) with a rotating copper anode mode at room temperature. The $\mathrm{CuK} \alpha$ radiation with a wavelength $\lambda=0.1542 \mathrm{~nm}$ was used. Equatorial diffractograms of the fibers were obtained from parallel bundles of fibers ( 100 pieces, average diameter of monofilament $12 \mu \mathrm{m}$ ).

Interplanar distances were calculated using the Bragg formula:

$$
\mathrm{d}=\lambda /(2 \sin (\theta))
$$

where $\lambda$ is the wavelength of the $\mathrm{X}$-ray radiation, and $\theta$ is the diffraction angle.

\section{Results and Discussion}

Cellulose and composite fibers were obtained by a dry-jet wet method. The SEM images of spun fibers with different contents of silicon-containing additives are illustrated in Figure 2. 


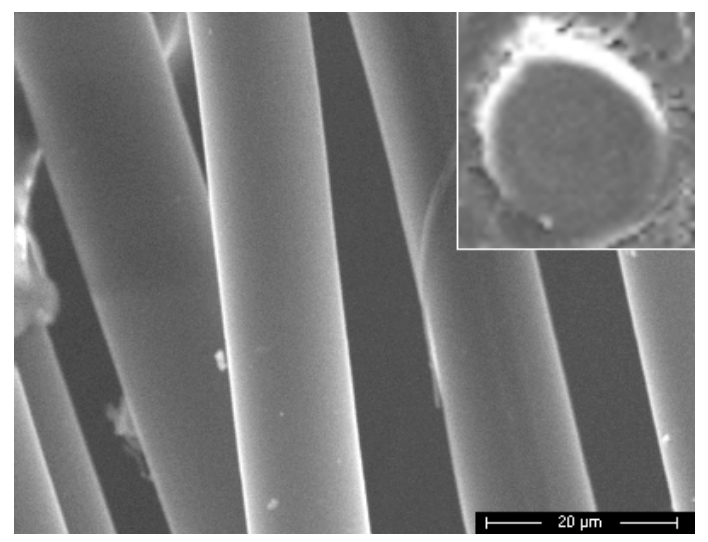

(a)

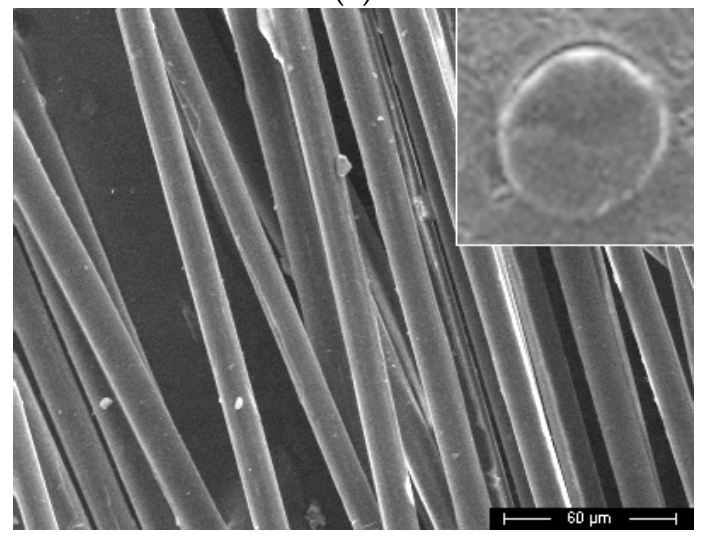

(c)

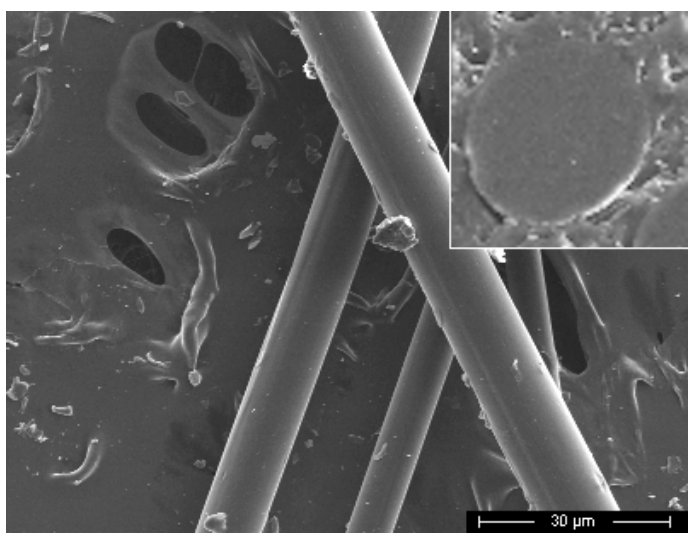

(b)

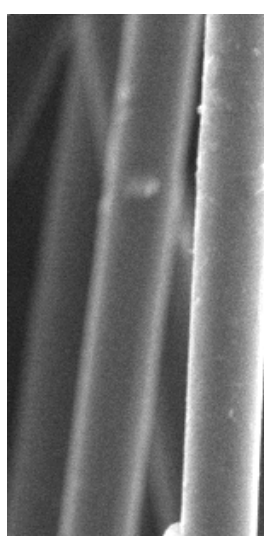

(d)

Figure 2. Microphotographs of surface and cross-section of cellulose (a), composite precursors $95 \%$ cellulose $+5 \%$ BTMSA (b), 90\% cellulose $+10 \%$ VTEOS (c), 95\% cellulose $+5 \%$ BTMSA (d).

As shown, the introduction of silicon-containing compounds into the cellulose matrix did not lead to a significant change in the morphology of the fibers. The surface and cross section of both cellulosic and composite fibers did not contain obvious defects. The cross-section was circular. The average diameter of the obtained fibers was 15 to 17 microns.

The structure of precursor fibers was one of the factors determining their properties, including mechanical and thermal behavior [26]. That is why before comparing the thermal properties of cellulose and composite fibers, their structure was studied with X-ray diffraction (Figure 3).

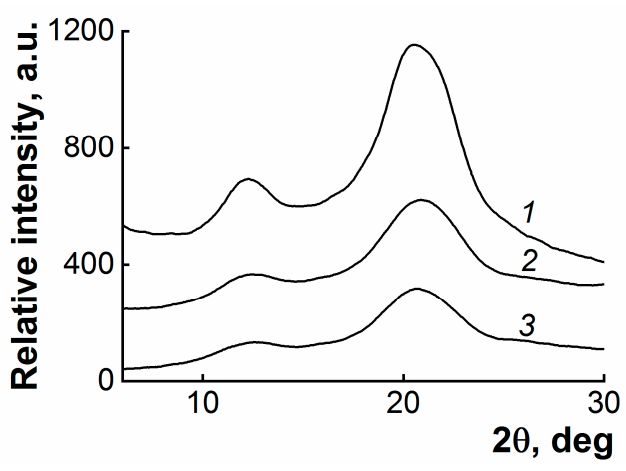

(a)

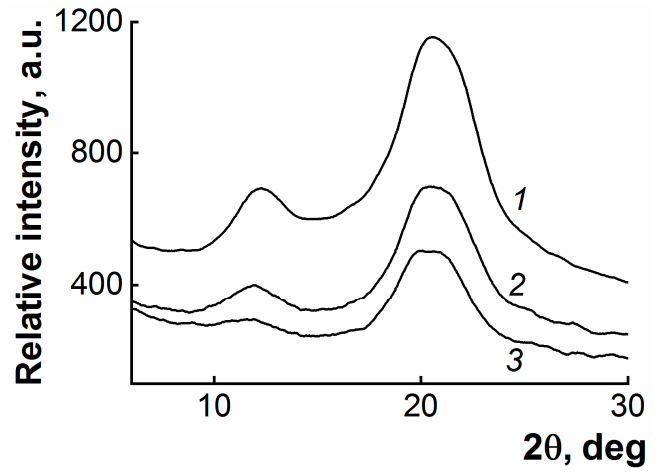

(b)

Figure 3. Cont. 


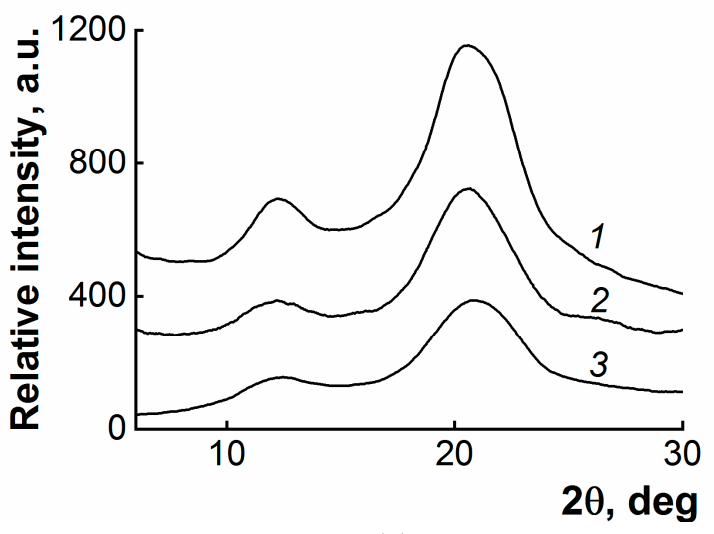

(c)

Figure 3. Equatorial diffractograms of cellulose (1) and composite fibers: (a) T-5 (2) and T-10 (3); (b) VT-5 (2) and VT-10 (3); (c) B-5 (2) and B-10 (3).

For all the samples studied, the main peaks are observed in regions $2 \theta \sim 12.3^{\circ}$ and $2 \theta \sim 20.6^{\circ}$ with interplanar distances of 3.61 and $2.19 \AA$, respectively. The positions of these peaks refer to the polymorphic form cellulose II [27]. The intensities of the peaks decrease with an increase in concentration of the additive, which indicates a partial disordering in the basal planes of the cellulose structure.

Unlike cellulose fibers, in which the carbon yield tends to be the minimum value with linear heating up to $1000{ }^{\circ} \mathrm{C}$, for almost all composite precursors the increase of the carbon yield was observed, which can be seen from the thermogravimetric curves in Figure 4 obtained at various temperature intervals.

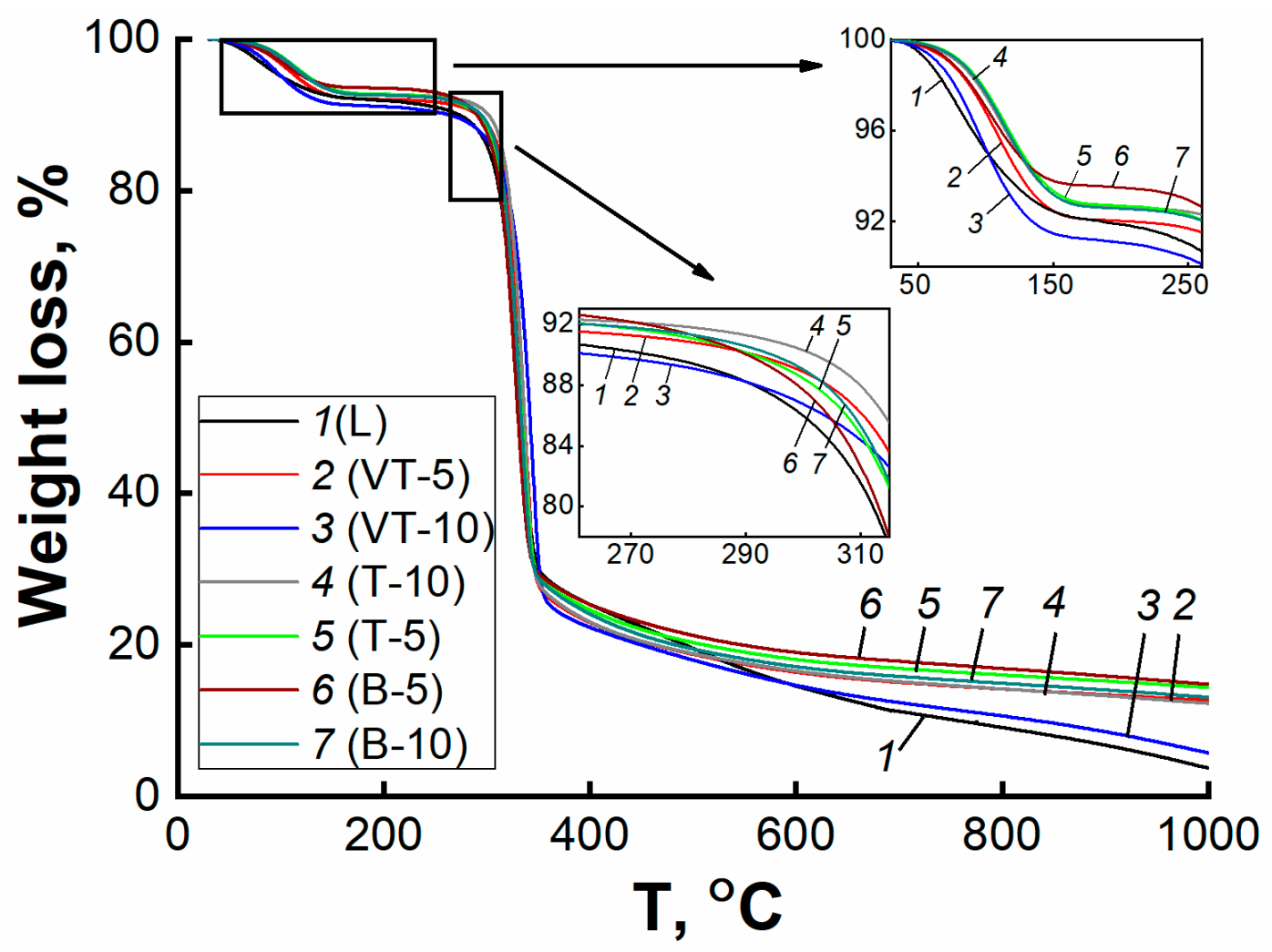

Figure 4. Thermogravimetry Analysis (TGA) curves of cellulose and composite fibers: complete curves and parts of the curves in the temperature ranges $30-260^{\circ} \mathrm{C}$ and $260-315^{\circ} \mathrm{C}$. Atmosphere: argon $10 \mathrm{~cm}^{3} / \mathrm{min}$. Linear heating at a rate of $10^{\circ} \mathrm{C} / \mathrm{min}$. 
When the samples were heated up to $200{ }^{\circ} \mathrm{C}$, the fibers lost $8-9 \%$ of their mass, which was stipulated with the adsorbed water removal. The highest rate of weight loss for cellulose fibers was observed up to $100{ }^{\circ} \mathrm{C}$. At further heating, VT-10 precursors lose water the most actively and this process continues up to $160{ }^{\circ} \mathrm{C}$. The process of removing water from T-10 fibers proceeds at the lowest rate and ends at around $200^{\circ} \mathrm{C}$. In the next stage of sample heating (in the temperature range $200-340^{\circ} \mathrm{C}$ ), two competing reactions occured-dehydration and depolymerization [28]. These reactions correspond to the extremes on the differential curves of the mass loss rate (DTG) (Figure 5).

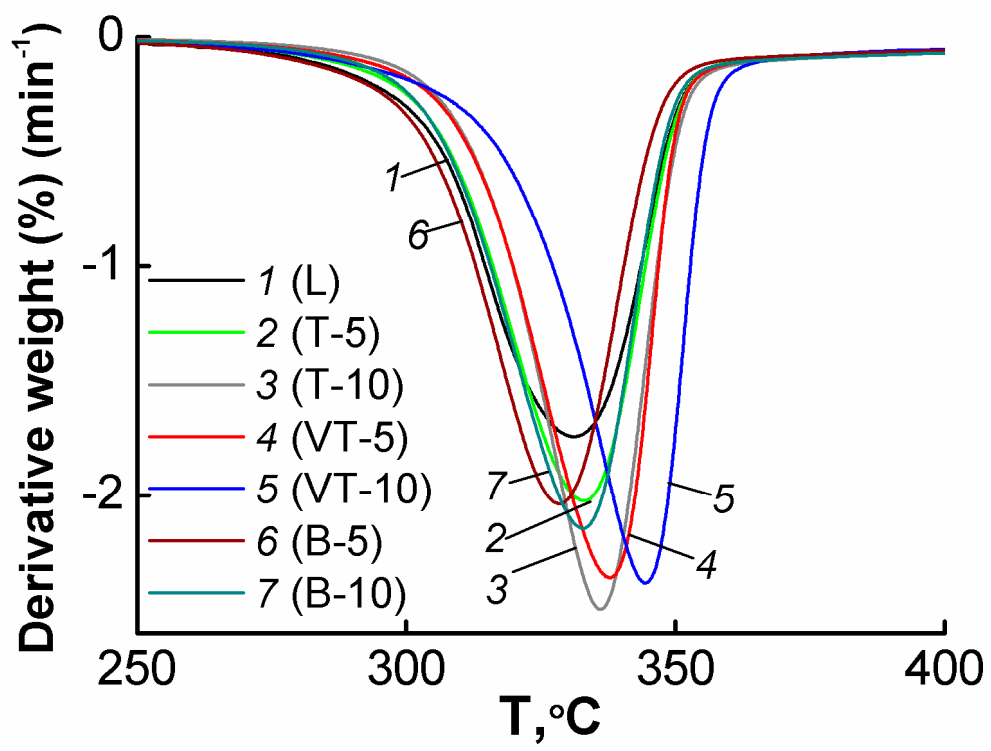

Figure 5. Mass loss rate (DTG) curves for cellulose and composite fibers.

Although the course of the DTG curves is the same, the positions of the temperatures at the beginning and the end of the decomposition reaction, as well as the maximum of the mass loss rate, differ. The temperatures corresponding to the extremum points and DTG $\mathrm{max}_{\max }$ values for all the testing samples are given in Table 3.

Table 3. Parameters of the thermodestruction rate of cellulose and composite fibers: the temperatures of minimums and the DTG values.

\begin{tabular}{crc}
\hline Sample & Tmax $^{\circ}{ }^{\circ} \mathbf{C}$ & DTGmax, \%/min \\
\hline L & 331 & -1.74 \\
T-5 & 332 & -2.02 \\
T-10 & 335 & -2.49 \\
VT-5 & 337 & -2.35 \\
VT-10 & 344 & -2.38 \\
B-5 & 328 & -2.03 \\
B-10 & 332 & -2.14 \\
\hline
\end{tabular}

The temperature range of pyrolysis, determined from the first derivative of the TGA curves, was used for estimation of the activation energy of thermal decomposition. According to [29], these values allow us not only to estimate the energy necessary for the reaction, but also the possible nature of the product obtained. For more accurate determination of the pyrolysis starting temperature, TGA derivatives of a higher order could be used. The corresponding temperature dependences of the weight loss rate is presented in Figure 6, and calculated activation energy, as well as intrinsic points of the decomposition process, is shown in Table 4. 


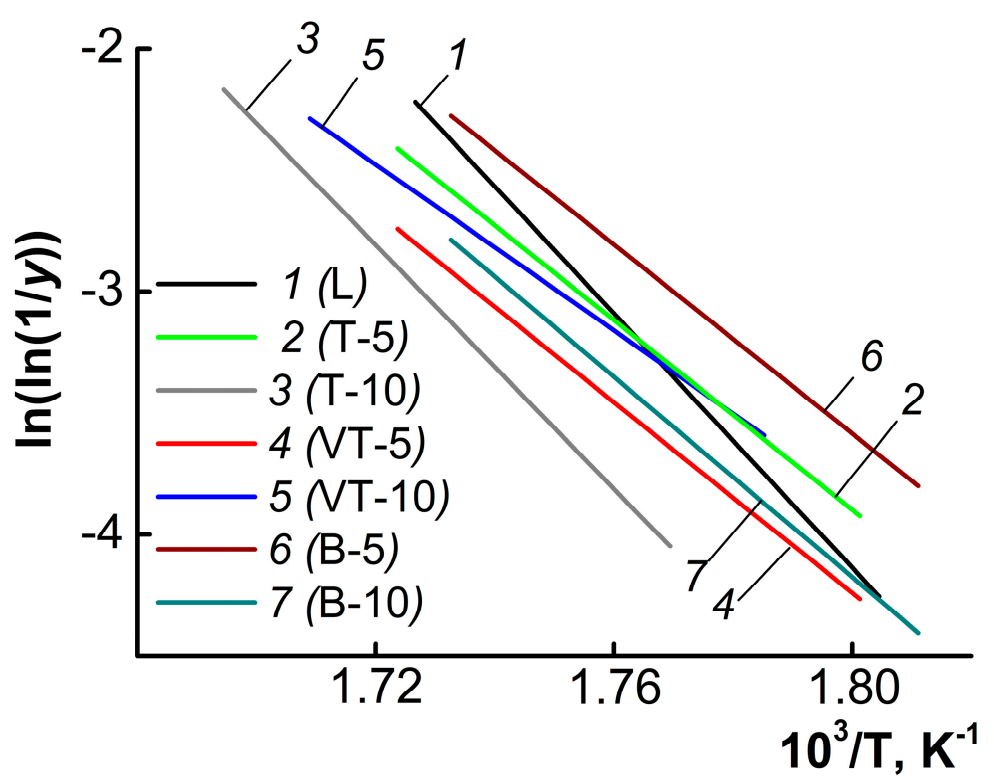

Figure 6. Dependence $\ln (\ln (1 / y))$ VS 1000/T for determining the activation energy of the thermal decomposition.

Table 4. DTG data for cellulose and composite fibers.

\begin{tabular}{cccccccc}
\hline Sample & L (1) & T-5 (2) & T-10 (3) & B-5 (6) & B-10 (7) & VT-5 (4) & VT-10 (5) \\
\hline Slope & -26.14 & -19.47 & -25.08 & -19.4 & -20.6 & -19.6 & -17.1 \\
$\mathrm{~T}_{\text {onset }},{ }^{\circ} \mathrm{C}$ & 281 & 282 & 292 & 279 & 279 & 282 & 287 \\
$\mathrm{~T}_{\text {range, }}{ }^{\circ} \mathrm{C}$ & $281-306$ & $282-307$ & $292-317$ & $279-304$ & $279-304$ & $282-307$ & $287-312$ \\
$E_{a}, \mathrm{~kJ} / \mathrm{mol}$ & 234 & 162 & 209 & 162 & 172 & 164 & 143 \\
Weight loss, $\%$ & 5.6 & 4.7 & 7 & 5.3 & 3.4 & 3.5 & 4.8 \\
Carbon yield at & 3.5 & 14.4 & 12.3 & 14.8 & 13.1 & 12.6 & 5.7 \\
$1000{ }^{\circ} \mathrm{C}, \%$ & & & & & & &
\end{tabular}

Thus, the lowest point of the pyrolysis starting $\left(279^{\circ} \mathrm{C}\right)$ was for the precursors B-5 and B-10, and the highest was for the sample T-10 $\left(292^{\circ} \mathrm{C}\right)$. All other formulations were located inside this temperature interval. This means that depending on the nature of the additive, the thermal stability of the samples was slightly varied. Reducing the structural order in the system did not lead to a decrease in thermal stability. Hence, it can be assumed that the chemical interaction between the silicon-containing additive and the cellulose matrix, and the amount of the additive, plays a more important role in the decomposition process than the crystalline structure. It is known that in the presence of water, organosilicon compounds are extremely unstable compounds, prone to hydrolysis reactions, and subsequent condensation and polycondensation with the formation of oligomers and polymers with siloxane bonds of a linear or cyclic structure [30,31]. In the studied cellulose solutions in NMMO, water was present in an amount of $\sim 10 \%$ to $13 \%$. The introduction of tetraethoxysilane (TEOS) to cellulose solutions in NMMO led to the formation of a discrete phase of polysiloxanes. The resulting polysiloxane particles were uniformly distributed in the cellulose matrix. The vinyltriethoxysilane (VTEOS) molecule contains double bonds that can open and integrate into cellulose chains during thermolysis, ensuring the formation of $\mathrm{Si}-\mathrm{C}$ bonds (as evidenced by IR spectroscopy). Bistrimethylsilyl acetylene (BTMSA) is chemically inert and does not chemically interact with the matrix when forming the fiber.

Based on the Broido method, the values of activation energy $\left(E_{a}\right)$ of the thermal decomposition for the spun fibers were calculated. The activation energy for Lyocell fibers was $234 \mathrm{~kJ} / \mathrm{mol}$, which is closer to the values for the cellulose samples discussed in [32-34]. The activation energy of the thermal decomposition of T-5, VT-5, and B-5 practically coincided. Further increases in the content of 
these additives in the system led to a multidirectional change in the activation energy. The value of $E_{a}$ increased for silyl-substituted additives and decreased for BTMSA. The maximum value of $209 \mathrm{~kJ} / \mathrm{mol}$ was achieved for T-10 samples. It should be noted that this value of $E_{a}$ is lower than that obtained for cellulose fibers.

Along with the highest activation energy for T-10 fibers, the highest mass loss rate was also recorded (Table 4). Lyocell fibers, on the contrary, were characterized by the lowest rate of mass loss. As a result, in the temperature range for which the activation energy was calculated, the largest mass loss of $7 \%$ was observed for the T-10 sample, while the BT- 5 and B-10 fibers lost about $3.5 \%$ of the initial mass only (Table 4). At $\mathrm{T}=1000{ }^{\circ} \mathrm{C}$, the carbon yield of the Lyocell fibers tended towards minimum values. The composite precursor T-5 samples had a carbon yield of $14.4 \%$ at the same temperature, which is the maximum value among all the samples studied. The minimum value (5.7\%) was observed for VT-10 fibers. It is important to note that despite the chemical nature of the additives introduced into the cellulose matrix, the carbon yield initially increased with the addition of $5 \%$ silicon-containing compounds, while a further increase in the additive to $10 \%$ led to a decrease in its value.

The DSC curves are shown in Figure 7.

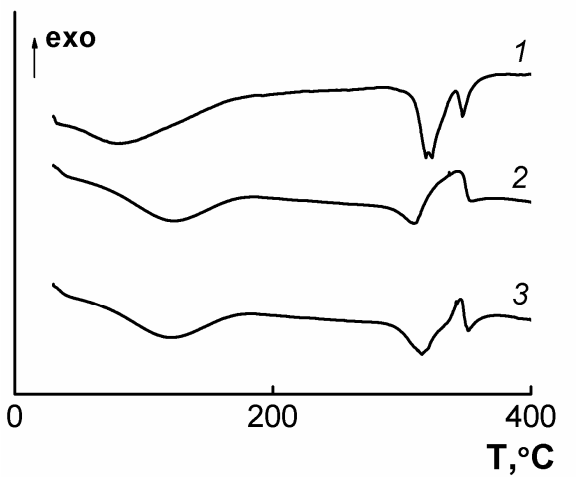

(a)

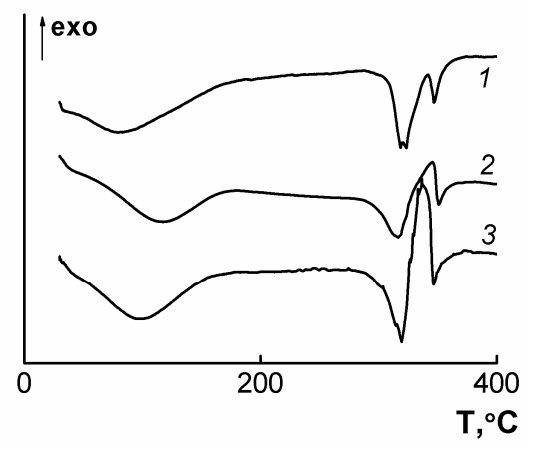

(b)

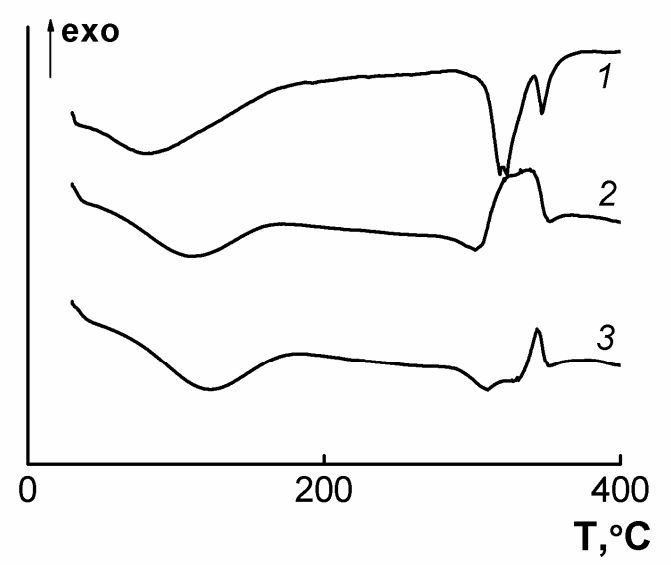

(c)

Figure 7. DSC curves for cellulose (1) and composite fibers: (a) T-5 (2), T-10 (3); (b) VT-5 (2), VT-10 (3); (c) B-5 (2) and B-10 (3). Atmosphere: argon $10 \mathrm{~cm}^{3} / \mathrm{min}$. Linear heating at a rate of $10{ }^{\circ} \mathrm{C} / \mathrm{min}$.

Table 5 summarizes the most important quantitative indicators of DSC data.

Two temperature ranges can be distinguished for all samples (Table 5). The first one $\left(30-178^{\circ} \mathrm{C}\right)$ characterizes an endothermic effect, connected to the removal of water. The second one is the thermal decomposition of cellulose (the temperature range of $286-376{ }^{\circ} \mathrm{C}$ ), accompanied by endo- and exo-effects. The described ranges are well correlated with the TGA data. 
Table 5. The main parameters of fibers obtained by DSC studies at a heating rate of $10 \mathrm{~K} / \mathrm{min}$ in an inert atmosphere.

\begin{tabular}{|c|c|c|c|c|c|c|c|c|c|c|c|c|}
\hline Sample & $\begin{array}{c}\text { Trange, } \\
{ }^{\circ} \mathrm{C}\end{array}$ & $\begin{array}{c}\text { Tmin } \\
\text { Endotherma, } \\
{ }^{\circ} \mathrm{C}\end{array}$ & $\begin{array}{l}\text { Endothermic } \\
\text { Effect, } J \cdot g^{-1}\end{array}$ & $\begin{array}{c}\text { Trange, } \\
{ }^{\circ} \mathrm{C}\end{array}$ & $\begin{array}{c}\text { Tmin } \\
\text { Endotherma, } \\
{ }^{\circ} \mathrm{C}\end{array}$ & $\begin{array}{l}\text { Endothermic } \\
\text { Effect, } \mathrm{J} \cdot \mathrm{g}^{-1}\end{array}$ & 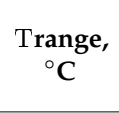 & $\begin{array}{c}\text { Tmax } \\
\text { Exotherma, } \\
\text { ' } \mathrm{C}\end{array}$ & $\begin{array}{l}\text { Exothermic } \\
\text { Effect, J.g }\end{array}$ & $\underset{{ }^{\circ} \mathrm{C}}{\text { Trange, }}$ & $\begin{array}{c}\text { Tmin } \\
\text { Endotherma, } \\
{ }^{\circ} \mathrm{C}\end{array}$ & $\begin{array}{l}\text { Endothermic } \\
\text { Effect, } J \cdot g^{-1}\end{array}$ \\
\hline $\mathrm{L}$ & $30-172$ & 77 & -162 & 288-345 & 326 & -119 & & & & $345-372$ & 350 & -25 \\
\hline T-5 & $30-178$ & 112 & -155 & 295-319 & 311 & -22 & 319-355 & 347 & 56 & & & \\
\hline T-10 & $30-177$ & 111 & -157 & $277-341$ & 317 & -66 & $342-351$ & 348 & 8 & $351-376$ & 354 & -11 \\
\hline VT-5 & $30-174$ & 106 & -178 & $286-333$ & 318 & -74 & $333-352$ & 348 & 18 & $352-370$ & 354 & -8 \\
\hline VT-10 & $30-177$ & 99 & -224 & $289-326$ & 323 & -95 & $326-345$ & 341 & 62 & $345-376$ & 351 & -14 \\
\hline B-5 & $30-164$ & 101 & -139 & $281-312$ & 305 & -10 & $312-357$ & 337 & 92 & & & \\
\hline B-10 & $30-177$ & 112 & -166 & $289-325$ & 312 & -10 & 339-355 & 347 & 19 & & & \\
\hline
\end{tabular}


The adsorbed water is the most quickly removed from the cellulose fibers, a minimum of the endotherm is observed at $77^{\circ} \mathrm{C}$. The introduction of additives into the cellulose matrix leads to a change in the kinetics of the water removal and the shift of the endothermal minimum to higher temperatures.

The dehydration and depolymerization reactions are accompanied by an endo-effect, which, depending on the type of additive and its concentration, starts at temperatures of $277-295{ }^{\circ} \mathrm{C}$. The endo-effect decreases dramatically for T-5, B-5, and B-10 fibers, while for silyl-substituted additives it increases with increasing additive concentration, and for composite fibers of series B it remains unchanged.

At higher temperatures, processes of gas formation $\left(\mathrm{CO}, \mathrm{CO}_{2}\right.$, etc.) [35] and their interaction with the transformed sample under study are observed, which are expressed as endo- and exo- peaks on the DSC curves.

With an increase in the VTEOS content up to $10 \%$, the thermal behavior of the system changes. On the DSC curve (Figure 7, curve 3), there are also three peaks, but the maximums of the peaks are shifted. Thus, the position of the endopeak corresponding to dehydration processes shifts to $323^{\circ} \mathrm{C}$, while the position of the maximum of the exopeak shifts toward lower temperatures to $341^{\circ} \mathrm{C}$. The character of the curve also changes. The increased content of the additive leads to a significant acceleration of the processes of structural rearrangements, as evidenced by the heat of the exo-effect that has increased almost 4-fold. The results obtained, at first glance, are somewhat different from the TGA data, according to which an increase in the VTEOS content in cellulose to $10 \%$ leads to a decrease in the carbon yield. Apparently, the processes occurring in the heat treatment process are more complex. It can be assumed that high heat release in the bulk of the sample initiates the flow of deeper destruction processes leading to the mass loss.

\section{Conclusions}

Thus, the introduction of silicon-containing additives into the cellulose matrix leads to a decrease in structure ordering and affects the thermal behavior of the resulting composite precursors. For all composite fibers, the activation energy of pyrolysis is less than that for cellulose fibers. At the same time, the reaction itself starts first for samples B-5 and B-10, and later on for T-10 fibers, i.e., the first type of additive acts as a pyrolysis catalyst, and the second one as a flame retardant. The type of observed peaks on the DSC curves for composite fibers cardinally changes from the endopeaks inherent for cellulose fibers by the combination of endo- and exo- peaks. This may indicate the occurrence of a number of complex chemical processes leading to an increase in the mass of the carbon yield at temperatures up to $1000^{\circ} \mathrm{C}$. Regardless of the type of silicon-containing agent, the maximum values of the carbon yield are achieved with the introduction of $5 \%$ of the composite additive into the cellulose. For further improvement of the values of fibers' carbon yield, it is necessary to optimize the temperature profiles and residence times. Additional impregnation of the discussed composite precursors with ammonium chloride, diammonium phosphate, or other silicon-containing compounds also contributes to an increase in carbon yield values and is the subject of further research. The resulting carbon fibers from composite precursors based on cellulose in the future can be used to create composite materials with unique engineering properties such as high thermal stability and mechanical values.

Author Contributions: M.M. and I.M. provided the idea for this study, proposed the experiments and wrote the paper; I.M. analyzed the data; L.G. analyzed the data and reviewed the paper; M.V. produced the composite samples; G.S. performed thermal analysis and discussed the data; I.L. investigated the structure of the fibers; M.M. and I.M. edited the final paper.

Funding: This research was funded by RFBR according to the research project No. 16-33-60218 mol_a_dk.

Conflicts of Interest: The authors declare no conflict of interest. 


\section{References}

1. Golova, L.K. Processing of Cellulose via Highly Concentrated “Solid Solutions". Fibre Chem. 1996, 28 , 5-16. [CrossRef]

2. Goldhalm, G. TENCEL ${ }^{\circledR}$ Carbon Precursor. Lenzinger Berichte 2012, 90, 58-63.

3. Konkin, A.A. Carbon and Other Heat-Resistant Fibrous Materials; Khimiya: Moscow, Russia, 1974.

4. Sporl, J.M.; Beyer, R.; Abels, F.; Cwik, T.; Muller, A.; Hermanutz, F.; Buchmeister, M.R. Cellulose-Derived Carbon Fibers with Improved Carbon Yield and Mechanical Properties. Macromol. Mater. Eng. 2017, 302, 1-10. [CrossRef]

5. Dumanl1, A.G.; Windle, A.H. Carbon Fibres From Cellulosic Precursors: A Review. J. Mater. Sci. 2012, 47, 4236-4250. [CrossRef]

6. $\quad$ Park, J.K.; Lee, J.Y.; Won, Y.G.; Cho, D.H. Method for Manufacturing Lyocell Based Carbon Fiber and Lyocell Based Carbon Fabric. Patent US 20100285223, 20 April 2010.

7. Chernenko, D.N. Development and Research of Technological Process of Obtaining Carbon Fabrics from Hydrated Cellulose Fibers. Bachelor's Thesis, Research Institute of Structural Materials based on graphite "NIIgraphit", Moscow, Russia, 2015.

8. Donnet, J.-B.; Bansal, R.C. Carbon Fibers, 3rd ed.; CRC Press: Boca Raton, FL, USA, 1998.

9. Kazakov, M.E.; Trushnikov, A.M.; Yunitskaya, M.L. The Method of Obtaining Carbon Fiber Material. Patent RF 2045472, 10 October 1995.

10. Olri, P.; Plezantene, E.; Louison, S.; Paye, R. Carbonization of Cellulosic Fibrous Materials in the Presence of an Organosilicon Compound. Patent RF 2256013, 10 July 2005.

11. Olri, P.; Louison, S.; Kazakov, M.E.; Trushnikov, A.M. The Method of Obtaining Carbon Fiber Material. Patent RF 2258773, 20 August 2005.

12. Karasev, J.V.; Lazarev, M.N.; Motorin, S.V.; Ozolin, A.A. Method for Continuous Production of Carbon Fiber from Hydrated Cellulose in the Form of a Unidirectional Tow. Patent RF 2429316, 20 September 2011.

13. Trushnikov, A.M.; Kazakov, M.E.; Gridina, Yu.F.; Vazheva, L.D.; Borisova, L.K. The Method of Obtaining Carbon Fiber Material. Patent RF 2047674, 10 November 1995.

14. Kopylov, V.M.; Trushnikov, A.M.; Khazanov, I.I.; Kazakov, M.E.; Nikitin, A.V.; Ratushnyak, M.A. The Method of Producing Carbon Fiber and Materials Based on it. Patent RF 2384657, 20 March 2010.

15. Makarov, I.S.; Golova, L.K.; Kuznetsova, L.K.; Bondarenko, G.N.; Skvortsov, I.Y.; Mironova, M.V.; Bermeshev, M.V. Composite Fibers Based on Cellulose and Tetraethoxysilane: Preparation, Structure and Properties. Fibre Chem. 2017, 49, 101-107. [CrossRef]

16. Wizon, I.; Robertson, J.A. Continuous Filament Ceramic Fibers via the Viscose Process. J. Polym. Sci. Part C 1967, 19, 267-281. [CrossRef]

17. Makarov, I.S.; Golova, L.K.; Bondarenko, G.N.; Skvortsov, I.Y.; Berkovich, A.K.; Bermeshev, M.V.; Mironova, M.V. Carbon-Silicon-Carbide Fibers Prepared from Solid Solutions of Cellulose in N-Methylmorpholine-N-Oxide with Added Tetraethoxysilane. Fibre Chem. 2017, 49, 231-236. [CrossRef]

18. Kablov, E.N. Materials and Chemical Technologies for Aircraft Engineering. Herald Russ. Academ. Sci. 2012, 82, 158-167. [CrossRef]

19. Godfrey, L.E.A. Differential Thermal Analysis (DTA) and Thermogravimetric Analysis (TGA) Studies of Flame-Retardant Rayon Fibers. Text. Res. J. 1970, 40, 116-126. [CrossRef]

20. Broido, A. A Simple, Sensitive Graphical Method of Treating Thermogravimetric Analysis Data. J. Polym. Sci. Part A-2 1969, 7, 1761-1773. [CrossRef]

21. Vecchio, S.; Luciano, G.; Franceschi, E. Explorative Kinetic Study on the Thermal Degradation of Five Wood Species for Application in the Archaeological Field. Annali di Chimica 2006, 96, 715-725. [CrossRef] [PubMed]

22. Tian, C.M.; Shi, Z.H.; Zhang, H.Y.; Xu, J.Z.; Shi, J.R.; Guo, H.Z. Thermal Degradation of Cotton Cellulose. J. Therm. Anal. Calorim. 1999, 55, 93-98. [CrossRef]

23. Loskutov, S.R.; Shapchenkova, O.A.; Aniskina, A.A. Thermal Analysis of Wood of the Main Tree Species of Central Siberia. Sib. J. For. Sci. 2015, 6, 17-30.

24. Wendlandt, W.W. Thermal Methods of Analysis; Interscience Publishers: New York, NY, USA, 1964.

25. Golova, L.K.; Vasilyeva, N.V.; Borodina, O.E.; Krylova, T.B.; Kuznetsova, L.K.; Rogovina, S.Z.; Zelenetskiy, S.N. A Method of Obtaining a Cellulose Solution for the Manufacture of Molded Products. Patent RF 1645308, 20 March 1997. 
26. Kulichikhin, V.G.; Skvortsov, I.Yu.; Mironova, M.V.; Ozerin, A.N.; Kurkin, T.S.; Berkovich, A.K.; Frenkin, E.I.; Malkin, A.Y. From Polyacrylonitrile, its Solutions, and Filaments to Carbon Fibers II. Spinning PAN-Precursors and their Thermal Treatment. Adv. Polym. Technol. 2018, 37, 1099-1113. [CrossRef]

27. Ford, E.N.J.; Mendon, S.K.; Thames, S.F.; Rawlins, J.W. X-ray Diffraction of Cotton Treated with Neutralized Vegetable Oil-based Macromolecular Crosslinkers. J. Eng. Fiber Fabr. 2010, 5, 10-20.

28. Capart, R.; Khezami, L.; Burnhamb, A.K. Assessment of Various Kinetic Models for the Pyrolysis of a Microgranular Cellulose. Thermochim. Acta 2004, 417, 79-89. [CrossRef]

29. Milosavljevic, I.; Suuberg, E.M. Cellulose Thermal Decomposition Kinetics: Global Mass Loss Kinetics. Ind. Eng. Chem. Res. 1995, 34, 1081-1091. [CrossRef]

30. Andrianov, K.A. Organosilicon Compounds; GHI: Moscow, Russia, 1955.

31. Kazakova, V.V.; Myakushev, V.D.; Strelkova, T.V.; Muzafarov, A.M. Hyperbranched Polyethoxysiloxanes: Synthesis and Properties. Polym. Sci. Ser. A 1999, 41, 283-291.

32. Ornaghi, H.L.; Poletto, M.; Zattera, A.J.; Amico, S.C. Correlation of the Thermal Stability and the Decomposition Kinetics of Six Different Vegetal Fibers. Cellulose 2014, 21, 177-188. [CrossRef]

33. Varhegyi, G.; Jakab, E.; Antal, M.J. Is the Broido-Shafizadeh Model for Cellulose Pyrolysis True? Energy Fuels 1994, 8, 1345-1352. [CrossRef]

34. Lin, T.; Goos, E.; Riedel, U. A Sectional Approach for Biomass: Modelling the Pyrolysis of Cellulose. Fuel Process. Technol. 2013, 115, 246-253. [CrossRef]

35. Yang, H.; Yan, R.; Chen, H.; Lee, D.H.; Zheng, C. Characteristics of Hemicellulose, Cellulose and Lignin Pyrolysis. Fuel 2007, 86, 1781-1788. [CrossRef]

(C) 2019 by the authors. Licensee MDPI, Basel, Switzerland. This article is an open access article distributed under the terms and conditions of the Creative Commons Attribution (CC BY) license (http://creativecommons.org/licenses/by/4.0/). 